\title{
Articles
}

\section{On integration of isolated pupils into the class using modern teaching methods}

\section{Bronislava Štěpánková, Petr Emanovský}

\begin{abstract}
Successful pedagogical work is unthinkable without good knowledge of relationships of pupils in the classroom. The knowledge is important especially in the case of a class of teenagers. The article deals with the issue of isolated pupils in such a class and the possibility to integrate them into the class using suitable modern teaching methods (project-based learning, cooperative learning, collaborative teaching/learning). The method as well as the process and results of the research connected with this problem at elementary school are described in this paper. The aim of the research was to answer the question: Can the project-based learning help isolated pupils integrate into the class? Using sociograms and the Wilcoxon statistic test of significance, the hypothesis was accepted that the number of isolates after the project-based learning is statistically significantly lower than that of the case of using the classical frontal teaching.
\end{abstract}

Key words: relationships of pupils, sociometry, isolates, project-based learning.

\section{Introduction}

The unpleasant feeling of isolation of an individual in a group of classmates, especially in the sensitive period of adolescence, can have a significant negative influence on her 
or his future life. To avoid this negative feeling and try to integrate the teenager back into the class team, we tried to find some means, method or form which would contribute to the integration. After some experience, we came to the conclusion that the method of project-based learning (PBL) could contribute to the inclusion of students standing at the edge of class to the class group. In order to ascertain the correctness of our view, we realized the research.

\section{Sociometry as a method to describe the relationships in the class}

Sociometry represents a quantitative method for measuring social relationships. It was developed by the psychotherapist J. L. Moreno in his studies of the relationship between social structures and psychological well-being (Moreno, 1953). One of the important means in sociometry is the sociogram, a systematic method for graphically representing individuals as points/nodes and the relationships between them as lines/ arcs (McIntyre, 2003). The graphically representing is based on a special sociometric test detecting pupils' positive and negative choices in the class. Sociometry and sociograms are undervalued tools for teachers' behaviour management in the class collective. They provide a wealth of information about classroom friendship and interaction patterns, and they can be very useful for the teacher when he/she is planning seating arrangements or work-group composition. The results of sociometric investigation can be applied to help make positive changes in behaviour in a classroom setting (Sherman, 2002).

\subsection{Sociometric structure of the class}

Sociograms help identify various groups of pupils. The pattern of choices can show a star (that is someone that receives the most choices), a rejectee (he or she that receives no positive choices and a number of negative choices); everyone else is a member (receiving some positive and perhaps some negative choices) and an isolate (someone receiving no choices). Sociometry is based on the fact that people make choices in interpersonal relationships. Whenever people gather, they make choices where to sit or stand; choices about who is perceived as friendly and who not, who is central to the group, who is rejected, who is isolated (Mclntyre, 2003). Sociometry can be seen as a way in which to measure the relationships between people in a social setting. It is undertaken to reveal information about individuals in their relationship to groups, in the context of their mutual activities. In education, sociometric assessment is a valuable means by which the teacher can determine the relationships of individual pupils 
to other ones within the class. It also allows the teacher to track the roles which the pupils play in mutual relationships within the classroom, identifying for example the popular children who are the centre of attention, and the neglected children who are overlooked by the majority of their peers (Hoffman, 2001).

\subsection{Sociometric test}

The sociometric test is the most important and basic technique giving sociometry information. Using the test we find out the positive choices in the group, which are sympathy, preferences, attractions, and also the negative choice - rejection. The positive choices are detected more often. The sociometric test contains usually one or more questions that allow all members of a social group to vote of the partners for certain situations or joint activities. The sociometric test is set mostly in written form. The content of the questions depends on the specific objectives of the sociometric investigation. The sociometric-rating questionnaire SO-RA-D by Vladimir Hrabal can be also included among the sociometric tests. It uses a rating scale for two factors - influence and popularity, which are supplemented by verbal reasoning of the assessments. The questionnaire is standardized for the population in the Czech Republic. In our research we have used the questionnaire B-3 which is designed for the sociometric analysis of pupils of the $4^{\text {th }}-9^{\text {th }}$ grades of primary school. The obtained data are usually processed in several ways - using matrix analysis, sociogram and calculation of sociometric indexes (Hoffman, 2001). For our purpose we created the sociograms using the freeware "Sociogram" and then determined the number of isolates (Table 1).

\section{Modern teaching methods as a support for isolates}

\subsection{Project-based learning}

Project-based learning is a learning method that places students at the center of the learning process. It is widely used to replace the traditional teaching method in which the teacher, who is the center, strictly follows the teaching plan. The teacher leads the students to the learning that they desire or the learning following the project objectives (Henry, 1994). Project-based learning is an instructional model that involves students in investigations of compelling problems that culminate in authentic products. Projects that make for stronger classroom learning opportunities can vary widely in subject matter and scope, and can be delivered at a wide range of grade levels (Kratochvílová, 2003). Projects grow out of challenging questions that cannot be answered by rote learning. Projects put students in an active role such as: problem solver, decision maker, investigator, or documentarian (Thomas, 1998). Students become more engaged in 
learning when they have a chance to dig into complex, challenging, and sometimes even messy problems that closely resemble real life. Project-based learning goes beyond generating students' interest. Well-designed projects encourage active inquiry and higher-level thinking (Thomas, 1998). One of the advantages of project-based learning is that pupils have the opportunity to work in a team. Through solving of tasks in groups the pupils acquire and develop communicative and social experience and skills, learn to help each other and learn to respect the opinion of others. They all have the opportunity to assert themselves, to exchange ideas, defend their positions or lead a team (Kratochvílová, 2003). Since the project is not involved in teaching trying to learn as much as possible in the shortest possible time, emphasizes the quality of teaching, which develops specific personality traits of students (activity, initiative, independence, creativity) (Grecmanová \& Urbanovská, 1997).

\subsection{Cooperative learning}

Cooperative learning, sometimes called small-group learning, is an instructional strategy in which small groups of students work together on a common task. The task can be as simple as solving a multi-step math problem together, or as complex as developing a design for a new kind of school. In some cases, each group member is individually accountable for part of the task; in other cases, group members work together without formal role assignments. Cooperative learning focuses on the processes that occur in the cooperation within groups, primarily on social interaction (Kasíková, 1997). Mutual understanding, willingness to cooperate, ability to help each other and responsibility for other are necessary to achieve a common goal. An important assumption for cooperation is a joint task for a group of pupils. Suitable conditions for the development of positive social relationships create in the classroom while they are solving the common task. Jana Trabalíková $(2011,2012)$ analyzes the relationship between class climate and cooperative learning.

\subsection{Collaborative learning}

Collaboration in teaching involves educators planning and working together in schools, working with students at all stages of schooling and across all learning areas. There is no one way of collaborating; each context is different. Collaborative teaching can take many forms; each school should choose the mode of collaboration which best suits learner needs. Some options are joint planning, small group work, parallel teaching, support teaching or team teaching. All forms of collaborative teaching should include assessment of learner performance/learning outcomes as well as evaluation of the unit of work/lesson sequence. Collaborative learning is any learning where two or more students are working together on a learning experience. It is learner-centred where stu- 
dents are active participants and have clear roles, responsibilities and outcomes - both long term and short term. The success of the group is dependent upon the contribution of every individual. Collaborative skills are important in many work and social contexts. The purpose of collaborative learning in schools is to give learners an avenue where they learn the skills of active listening, positive conflict resolution and awareness/acceptance of others' views (ESL FundameNTals, 2004).

\section{Research}

The following research problem was formulated for the investigation: Does project-based learning help isolated pupils integrate into the class collective? The research hypothesis was formulated according to the research problem: Project-based learning helps isolates with integration into the class more than frontal teaching.

The research hypothesis was transformed to the statistic hypothesis:

The number of isolates determined using sociometric investigation after project-based learning is lower than the number of isolates determined using sociometric investigation after frontal teaching.

Subsequently, the null and alternative hypotheses were formulated:

$H_{0}$ : The number of isolates within frontal teaching is the same as within project-based learning.

$H_{A}$ : The number of isolates within frontal teaching is different than within project-based learning.

\subsection{Research method}

The sociometric-rating questionnaire B-3 SORAD by Vladimír Hrabal was used to determine the number of isolates after using project-based learning and after frontal teaching. This questionnaire was chosen because it allows an easy computer processing in the form of class hierarchy, where it is easy to recognize the names of children that represent the isolates. Moreover, the sociogram of positive relations as well as the sociogram of negative relations is given. Special attention was paid to such isolates that were labelled with the same order number in the sociogram and in the class hierarchy. If a positive relation from an isolate to a pupil of the rest of class is found, these two pupils will be assigned to one working group with the intention of strengthening of positive linkages. 
The form of the questionnaire B-3 is the following:

1. My friends in our class include:

1. 3 points

2. 2 points

3. 1 points

2. As a boyfriend/girlfriend I would not choose:

1. 3 points

2. 2 points

3. 1 points

3. I evaluate myself as follows:
a) I am always at the centre stage in the classroom.
b) Sometimes I participate and I am usually informed of events in the classroom.
c) A couple of times I participated in, but I do not use to be informed.
d) It seems that the class does not care about my participation too much.
e) I am not interested in the events in the classroom.

4. Answer yes - no:

In the classroom there is at least one pupil who is unhappy.

yes - no

Who is it?

Why is he/she unhappy?

There is someone in the class that the others hurt occasionally. yes - no

Who is it?

Why they hurt him/her?

Sometimes I'm looking forward to school.

yes - no

Mostly I find someone who can help me with a problem.

yes - no

We deal with common problems mostly in peace.

yes - no

5. Circle the number in each row which best expresses the degree of your feelings in the classroom:

Feeling of security

Feeling of friendship

Atmosphere of cooperation

Feeling of confidence

Tolerance
1234567

1234567

1234567

1234567

1234567
Feeling of threat

Feeling of antagonism

Atmosphere of indifference

Feeling of distrust

Intolerance

6. Find someone in the class that is:

Righteous

Reliable

Offensive

Unjust 
Witty

Always at the center of the action

On good terms with all
Ungrateful

Unreliable

Alone

\subsection{Evaluation and interpretation of the sociometric questionnaire}

The questionnaire refers to the class dynamics. Sociometric stars, isolates as well as individuals at risk - potential victims of aggressors and aggressors themselves can be identified using the questionnaire. Class potential is also described by responses of pupils connected with their positions in the class, so we can find out those who are not comfortable in the classroom. The properties projected to the classmates represent also a very valuable source of information. The class positions hierarchy is built from several outputs of the questionnaire, and therefore it can be suitably used as a basis for intervention in the class. Sociometric stars have the largest radius in the classroom, their views are respected, and so they can streamline the educational intervention of the teacher. The rejected individuals can be also be identified through the results of the questionnaire. They are the easiest victims of the class, and we would like to know how they are satisfied in the class collective. In the case of negative feelings of the pupil is necessary to find the cause and try to change his/her position. In the case of the isolates it is necessary to try to integrate them into the class collective.

\subsection{Preliminary research}

The preliminary research was realized on a small sample of two classes of the seventh grade. The isolates were determined using the sociometric questionnaire B-3 and subsequently working groups were created so that each group contained an isolated pupil. That was followed by one-day implementation of project-based learning and the same questionnaire was submitted to the students after the teaching. The order of the small sample sociometric measurement was to determine whether the number of the isolates in the class decreases after the implementation of project-based learning. Given the small number of classes it was not possible to use the statistical Wilcoxon test. Considered was the frequency of isolates before and after the implementation of project-based learning here.

\subsection{Research sample}

The research was carried out in the seventh, eighth and ninth grades of primary school. A total of 178 pupils took part in the research. 


\subsection{Process of research}

The sociometric questionnaire B-3 was submitted to the pupils of the research group at the end of November 2011 after the previous one-month period of using classical frontal teaching without any project-based method in the classes. Working groups for the project were created based on the subsequent computer data processing of the questionnaire. The "Project Day" took place in such distributed classes in the following period, when each class was processing its topic. The classes did not mix each other during this period. The sociometric questionnaire B-3 was answered by the pupils after the project again. The names of the isolated pupils were obtained from the class hierarchy based on the following computer processing of the second questionnaire. The number that represents the position in the class hierarchy is obtained summing all positive options and substracting all negative ones. The "sociometric stars" have the most points and the isolates have the fewest points.

\subsection{Sociometric results}

The following table shows the sociometric results connecting with the number of isolates in the classes obtained from the questionnaire.

Table 1: Sociometric results - number of isolates

\begin{tabular}{|l|r|r|r|r|r|r|r|r|r|}
\hline & 7.A & 7.B & 7.C & 8.A & $8 . B$ & $9 . A$ & $9 . B$ & $9 . C$ & S \\
\hline Number of pupils in the class & 19 & 20 & 25 & 23 & 23 & 24 & 23 & 21 & 178 \\
\hline Number of isolates before PBL & 5 & 8 & 10 & 9 & 8 & 8 & 7 & 5 & 60 \\
\hline Number of isolates after PBL & 3 & 5 & 7 & 10 & 6 & 5 & 4 & 5 & 45 \\
\hline
\end{tabular}

\subsection{Null hypothesis testing}

The statistical Wilcoxon test was used to test the null hypothesis. The test is usually used in the case of repeated measurements of the same objects. The advantage of the test is that it reveals small differences between the measurements. 
Table 2: Data for the Wilcoxon test

\begin{tabular}{|c|c|c|c|c|c|c|}
\hline \multirow{2}{*}{ Class } & \multicolumn{2}{|c|}{ Number of isolates } & \multirow{2}{*}{ d } & \multirow{2}{*}{ Order } & \multirow{2}{*}{+} & \multirow{2}{*}{ - } \\
\hline & Before using PBL & After using PBL & & & & \\
\hline 7. A & 5 & 3 & 2 & 2.5 & 2.5 & \\
\hline 7. $B$ & 8 & 5 & 3 & 5.5 & 5.5 & \\
\hline 7. $\mathrm{C}$ & 10 & 7 & 3 & 5.5 & 5.5 & \\
\hline 8. A & 9 & 10 & -1 & 1 & & 1 \\
\hline 8. B & 8 & 6 & 2 & 2.5 & 2.5 & \\
\hline 9. A & 8 & 5 & 3 & 5.5 & 5.5 & \\
\hline 9. B & 7 & 4 & 3 & 5.5 & 5.5 & \\
\hline 9. C & 5 & 5 & 0 & - & - & - \\
\hline
\end{tabular}

Using the data from Table 2 one can compute the value of the Wilcoxon test criterion $T=1$ (for details see e.g. Chráska, 2007). Since the table value of the criterion $T_{0.05}(7)$ for significance level $a=0.05$ and for 7 pairs is equal to $2>1$, the hypothesis $H_{0}$ is rejected. It means that for this significance level there is a statistically significant difference between the number of isolates after frontal teaching and that of after project-based learning.

\subsection{Conclusion of the research}

The Wilcoxon test showed that the number of isolates within the frontal teaching and project-based learning is different. The number of isolates occurring in the class before implementation of the project method, i. e. within the classical frontal teaching, is higher than after using the project-based education. One can say that the project-based learning represents an effective means for integration of isolates to the class collective. Thus, the validity of our research hypothesis about usefulness of project-based learning for integration of isolates into the class was confirmed.

\section{Summary}

Based on the data obtained from the sociometric investigation made in the seventh, eighth and ninth grades of primary school, we tried to determine whether projectbased learning helps the integration of isolates into the class team more in comparison with frontal teaching. The survey showed that the number of students ranking in a hierarchical arrangement of the class in the category of isolates decreased using the project-based method compared to the number of isolates within the frontal teaching. 
This result is considered to be very valuable. Project-based learning that gets more positive, and therefore we consider it appropriate to implement into teaching. It is an illusion that projects are the only way of including isolates into the class, but the results of our research have confirmed that they are one of the ways for marginalised children to be incorporated into a team. A comparison of the modern teaching methods in the context of pupils' relationships improvement could be an interesting topic for further research.

\section{References}

Chapin, F. S. (1950). Sociometric Stars and Isolates. American Journal of Sociology, Vol. 56, pp. 263-267. Chráska, M. (2007). Methods of Pedagogical Research. Praha: Grada.

Baranoková, E. (2012). Project-based Learning as Help for Marginalized Children. Diploma Thesis, Palacký University, Olomouc.

Grecmanová, H. \& Urbanovská, E. (1997). Project-based Learning and its Importance at the Current School. Pedagogika, vol. 1, pp. 37-45.

Henry, J. (1994). Teaching Through Projects, London: Kogan Page Limited.

Hoffman, C. (2001). Introduction to Sociometry. Retrieved from: http://www.hoopandtree.org/ sociometry.htm

Kasíková, H. (1997). Cooperative Teaching, Cooperative School, Praha: Portál.

Kratochvílová, J. (2003). Theory and Practice of Project-based Learning. Brno: Pedagogická fakulta MU.

Lodico, M. G., Spaulding, D. T. \& Voeghtle, K. H. (2010). Methods in Educational Research. San Francisco: Jossey-Bass A Wiley Imprint.

McIntyre, T. (2003). Sociograms. Retrieved from: http://maxweber.hunter.cuny.edy/pub/eres/ EDSPC715_MCINTYRE/Sociogram.html

Moreno, J. L. (1953). Who Shall Survive? Foundations of Sociometry, Group Psychotherapy and Sociodrama. Beacon House, Inc.

Sherman, L. (2002). Sociometry in the Classroom. Retrieved from: http://www.users.muohio.edu/ shermalw/sociometryfiles/socio_arehtmlx\#what.

Sociogram, freeware. Retrieved from: http://www.phenotyping.com/sociogram/mSociogram.html Thomas, J. W. (1998). Project-based Learning: Overview. Novato, CA: Buck Institute for Education.

Trabalíková, J. (2011). Cooperative Teaching and its Influnce on Climate in the Classroom of $5^{\text {th }}$ Grade of Elementary School. PEDAGOGIKA.SK, Vol. 2 (No. 1), pp. 36-52.

Trabalíková, J. (2012). Action plan of a teacher in his/her own class. E-pedagogium [online]. 2012, II. [cit. 2012-10-20], pp. 71-93. ISSN 1213-7499. Retrieved from: http://www.upol.cz/fakulty/ pdf/e-pedagogium.

Understandings and strategies that underpin ESL pedagogy and practice. ESL FundameNTals. (2004). Retrieved from: http://www.det.nt.gov.au/_data/assets/pdf_file/0015/5244/esl_fundamentals.pdf 


\section{Acknowledgement}

This work was supported by the project CZ.1.07/2.2.00/15.0310 "Professional Science Teacher Training for Careers in a Competitive Environment".

\section{Contacts:}

PaedDr. Bronislava Štěpánková, Ph.D.

Institute of Education and Social Studies, Faculty of Education,

Palacký University, Olomouc, Czech Republic

E-mail: bronislava.stepankova@upol.cz

doc. RNDr. Petr Emanovský, Ph.D.

Department of Algebra and Geometry, Faculty of Science,

Palacký University, Olomouc, Czech Republic.

E-mail: petr.emanovsky@upol.cz

\section{IJAS Conference in Toronto}

The "International Journal of Arts and Sciences" Conference Series takes place annually in several cities across Europe and North America. One of the traditional international conferences was organized from May 19 to May 222013 at Ryerson University in Toronto, Canada. The conference brought together more than 100 international academics from around the world, including professors and graduate students, to present research in their respective fields. There were many interesting talks presented in four sections: Social Sciences and Humanities, Business and Economics, Teaching and Education and Technology and Science. The IJAS Conferences are typical multidisciplinary conferences where each participant can find a topic that interests her/him. Not otherwise it was in the pleasant environment of Ryerson University. 